\title{
The Effects of Written Emotional Disclosure to Subjective Distress and Mood on Individuals Experiencing Heartbreak
}

\author{
Sri Izzati ${ }^{1}$, Bagus Takwin ${ }^{2}$ \\ 1,2. Department of Psychology, Universitas Indonesia, Depok, Indonesia \\ *E-mail: sri.izzati@ui.ac.id
}

\begin{abstract}
Emotional distress caused by heartbreak can lead one to negative effects such as an increase of physical illness risks and stress-related diseases. Confiding in others about upsetting experiences such as heartbreak can be one of many ways to help one feel better, but not all are comfortable in sharing personal stories and not all heartbreak stories can be discussed easily. This research is conducted to examine the effects of written emotional disclosure (WED) to subjective distress and mood on individuals experiencing heartbreak. 15 male and 28 female undergraduates were randomly assigned to an experimental group to write expressively about their heartbreak, or to a control group to write about control topics. Subjective distress and mood were assessed using the adapted Impact of Event Scale and The Profile of Mood States-Revised. Using independent sample t-test and mixed ANOVA, research findings indicated significant mood improvement from the first to last day of writing session $F(1,6$, $65,8)=10,98, p<0,001$, but not a significant difference in subjective distress and mood between the two groups $F(1,41)<1, r=0,044$. The result suggested several considerations for future research with further explorations of the WED's benefits and mechanism, especially on individuals experiencing heartbreak.
\end{abstract}

Keywords: emotional inhibition; expressive writing; heartbreak; mood; subjective distress; written emotional disclosure

\section{Introduction}

Every individual grows and develops through various events in his life. Those events surely contribute various things to the individual to be learned and valued, which then become part of one's self. Of course, those various events are not limited to only the pleasant ones, but also stressful events or even traumatic, making one feel various kinds of negative emotions which may imply some certain significant effects to his life. From many kinds of stressful events one may have experienced, a heartbreak could possibly be one of them, especially for young-adults, who according to Erikson's theory, are on the development stage of intimacy versus isolation (Erikson, 1968). At this stage, young adults are either on the run to develop intimate relationship with other individuals, or being socially isolated (Erikson, 1968). The strive to form such intimacy usually involves various possible processes and journey, including failures in forming and maintaining intimate relationship with the expected individual, which then lead one to heartbreak and farewell, is a very natural and normal phase.
The effects of heartbreak on individuals experiencing it should not be underestimated. Not only one should deal with rejection, loneliness, or guilt, heartbreak can also result in emotional distress and grief responses (Kaczmarek et al., 1990 in Lepore \& Greenberg, 2002). At the extreme level, emotional distress from a heartbreak that one must bear may lead a person to horrid scenes, such as psychopathology (e.g., depression) or even death (Field, 2011). In 2014, $61 \%$ of 165 college students committed suicide due to depression, and $21 \%$ of them had relationship issues (National Survey of College Counseling Centers; Gallagher, 2014). Furthermore, in 2016, the survey conducted by the Association for University and College Counseling Center Director (Reetz, Bershad, LeViness, \& Whitlock, 2016) showed that the severity of mental illness among college students increased to $57,1 \%$; with an average of $41,23 \%$ students reported depression and $34,2 \%$ reported relationship issues. In Indonesia, although perhaps not yet summarized in official surveys, similar cases of depression and even suicides because of heartbreak are no longer some surprising news. 
One may respond variously to his stressful or traumatic experiences, and confiding in others about upsetting experiences can be one of many ways to help one feel better. However, not everyone is comfortable in sharing their personal stories and not every stories - particularly the stressful ones - can be easily discussed, which also includes heartbreak. What one would usually do is restrain himself, keeping his feelings and thoughts on the upsetting things or events all to himself. In addition to that, one may also inhibit his behavior, facial expressions, and language, and actively fights the urge to think about the things related to the concealed information because of its aversive and unresolved nature (Pennebaker \& Beall, 1986).

Forms of inhibiting one's emotions, thoughts, and feelings; unwilling to talk about or to face the huge changes in life that involves a lot of emotions, is known with the term 'emotional inhibition'. In general, inhibiting emotions about upsetting experiences is not necessarily the best way that can be done to make one simply feel better, but may put him in situations full of more negative things. According to Pennebaker and Beall (1986) study, an active emotional inhibition is one of the longterm stressors which may cause or exacerbate both physical and mental illness and psychosomatic processes, thereby increasing the risk of other stress-related pathology and diseases (Pennebaker, 1997).

Just as constraining thoughts, feelings, or behavior related to the emotional upheaval is stressful, letting go and talking about these experiences should, in theory, reduce the stress of inhibition (Pennebaker, 1997). There are findings which suggest that confronting deeply personal issues may promote physical health, subjective wellbeing, and selected adaptive behaviors (Pennebaker, 1997). Forms of self-expression were found beneficial for individuals in terms of therapy, both in verbal and written forms (Wright, 2002). Writing was also found to have significant role in helping one to process his emotions and reduce chronic avoidance patterns (Sloan \& Marx, 2004; Swanbon, Boyce, \& Greenberg, 2008). Furthermore, a mere act of disclosure is in fact a powerful therapeutic agent that may account for an individual's healing process (Pennebaker, 1997). One of the disclosure forms that appears to be helpful and beneficial is written emotional disclosure by Pennebaker and Beall, 1986.

Written emotional disclosure (WED), is a procedure in which participants are asked to write about their most upsetting, stressful, or traumatic experiences (Pennebaker \& Beall, 1986). In the procedure, participants write about their deepest thoughts and feelings associated with a specified or self-selected stressful events for 20 minutes per day, for a typical 3-day period. In their writings, they are to describe the emotional information as detailed and specific as possible. Throughout the procedure, there is no feedback given.

Many previous studies on WED showed that such writing procedure was associated with a lot of health benefits: physical, psychological, and psychosocial, among various samples and contexts (Lepore \& Greenberg, 2002). A meta-analysis conducted by Smyth (1966) on the studies of WED, for example, set forth that writing about emotional topics resulted in significant reduction of stress. Significant decrease in depression and posttraumatic stress disorder (PTSD) symptoms, as well as improvements in the aspect of mood and other indicators of well-being have also been found as a benefit of writing (Sloan \& Marx, 2004a; Sloan, Marx, \& Epstein, 2005; Sloan, Marx, Epstein, \& Lexington, 2007). Although not yet popular, there also some research on the effectiveness of writing as a coping strategy has been conducted in Indonesia. For instance, in 2005, Purwandari and Hadi (2005) examined the effects of WED to the decrease of depression on male Indonesian teenagers who went through drugs rehabilitation, and reported that writing about emotional experiences had a significantly effective impact in reducing depression among teenagers. However, conducting a similar study on WED among vocational school students in Surabaya, Murti (2012) did not find the same significant effect. In line with Murti's findings (2012), a study by Sindoro (2016) on college students also showed that there is no significant reduction in psychology distress level on groups doing the WED procedure.

The purpose of this research is to reexamine whether the WED method can be applied in Indonesia, and specifically, to individuals experiencing heartbreak. Unlike the previous researches, this research aimed to look at the effects of WED to subjective distress and mood; aspects that are considered to be one of the simplest and most basic, yet are capable to put huge, significant impact on one's health and functionality. Furthermore, this study specially pinpointed individuals with emotional inhibition as a form of research control. 
Emotional inhibition. In this research, emotional inhibition is defined as the form of inhibiting one's expression of emotions, thoughts, and feelings (Pennebaker \& Beall, 1986). One who actively inhibits his emotions would be more likely to consciously constrain himself from thinking, feeling, or behaving, and would also be unwilling to talk about or deal with life changes (Pennebaker \& Beall, 1986; Pennebaker, 1989). Emotional inhibition is also associated with the changes in cognitive processing which can impact one negatively. By inhibiting significant thoughts and feelings linked to an event, one usually does not process the event thoroughly, and does not transform the event into language (Pennebaker, 1989). On the contrary, the process of translating the event into language will help the individual to understand and assimilate it (Pennebaker, 1989). As a consequence, the inhibited significant experiences will tend to remain in forms of ruminations, dreams, and other cognitive symptoms.

Subjective distress. This research focused on examining the effects of WED to stress, particularly subjective distress, which was manifested in forms of intrusion and avoidance. Intrusion was characterized by "unbidden thoughts and images, troubled dreams, strong pangs or waves of feelings, and repetitive behavior", and avoidance was characterized by "ideational constriction, denial of the meanings and consequences of the event, blunted sensation, behavioral inhibition or counterphobic activity, and awareness of emotional numbness" (Horowitz et al., 1979).

Mood. According to Oxford Dictionary of Psychology (2006), mood is defined as "a temporary but relatively sustained and pervasive affective state". Five dimensions of mood measured in this study is tension-anxiety, depression-rejection, fatigue-inertia, vigoractivity, confusion-bewilderment, and angerhostility, which referred to the Profile of Mood States (POMS) developed by McNair, Lorr, and Droppleman (1971, in Grove \& Prapavessis, 1992). According to Terry (1999), Anger is "typified by feelings which vary in intensity from mild annoyance or aggravation to fury and rage and is associated with arousal of the autonomic nervous system" (Spielberger, 1991, in Tery, 1999); Confusion is proposed to be "a feeling state characterized by feelings of bewilderment, uncertainty, and is associated with a general failure to control attention and emotions"; Depression is associated with "a negative self-schema characterized by themes such as hopelessness, personal deficiency, worthlessness, and selfblame" (Beck and Clark, 1988, in Terry, 1999); and Fatigue is "typified by feelings of mental and physical tiredness", while Tension is "typified by feelings such as nervousness, apprehension, worry, and anxiety". Lastly, Vigour is "typified by feelings of excitement, alertness, and physical energy".

The concept of WED was originally introduced by Pennebaker and Beall (1986) as an intervention to help individuals confront and process their reactions towards stressful life events (Lepore \& Greenberg, 2002). Previous studies stated that WED resulted in physiological release, thus reducing health risks and physiological tension associated with prolonged inhibition to disclose (Pennebaker, 1989). In accordance to this approach, past trauma, especially ones involving, shame or social stigma, is the most proper subject to be disclosed for those things are usually inhibited (Lepore \& Greenberg, 2002). From the cognitive perspective, talking about or confronting traumatic events can help one to organize, assimilate, and categorize his experiences into one meaningful framework (Meichenbaum, 1997; Horowitz, 1976; Silver \& Wortman, 1980, dalam Pennebaker \& Beall, 1986).

Stressful events, according to cognitive models of disclosure, they "contain novel information that is difficult to reconcile with prior assumptions about the self and the world" (Lepore \& Greenberg, 2002). Thus, these events are stored in active, short-term memory in forms of different cognitive fragments (Lepore \& Greenberg, 2002). Active memory tends to repeat its contents, resulting in thoughts, images, dreams, or feelings intrude in awareness (Horowitz, 1986). Intrusions arises from the uncomfortable discrepancy between the trauma and existing schemas, leading individuals to deny, avoid, or suppress these responses (Lepore \& Greenberg, 2002). Cognitive processing of these events involves alternating between intrusive and avoidance reactions, and slowly leads to reappraisal of the events or modification of scheme to cut the discrepancy in between (Lepore \& Greenberg, 2002).

Not all individuals are able do this cognitive transformation. Their awareness of the cognitive discrepancy leads to prolonged, intense instrusive states or rigid dysfunctional avoidance, which can be an ongoing source of internal stress, and also may be implicated in both mental and physical 
health problems (Baum et al., 1993; Lepore \& Helgeson, 1998). Here is where WED and subjective distress are linked. The WED procedure arises cognitive assimilation and organization, and new perspectives as well, thus reducing the frequency of subjective distress (intrusions and avoidance) (Pennebaker, 1989). WED may facilitate cognitive processing by alternating meanings or significance of the trauma to make it more consistent with what the individual believes about his self and his world (Lepore \& Greenberg, 2002; Pennebaker, 1989). By writing, individuals can organize their experiences into one coherent narrative, giving them new perspectives, problem understanding, and coping strategy (Smyth \& Greenberg, 2002, in Lepore \& Greenberg, 2002). In relation of WED and mood, there are findings suggesting that writing therapy is also effective in increasing individual's positive affect (Pennebaker \& Francis, 1996; Petrie, Booth, Pennebaker, Davison, \& Thomas, 1995; Spera, Buhrfeind, \& Pennebaker, 1994).

\section{Methods}

Sample. Participants were Universitas Indonesia undergraduate students who experienced heartbreak between January and April 2017 and met the emotional inhibition criteria (a score of $\geq$ 32 based on the Emotional Inhibition Scale) (Kellner, 1981, dalam Grandi, Sirri, Wise, Tossani, \& Fava, 2011). Potential participants were screened using an online recruitment questionnaire in which the Emotional Inhibition Scale was included. Of the 330 potential participants who met the characteristics that were contacted and asked to volunteer for this 3-day study, 43 participants agreed to participate and completed the whole study.

Research Design. We used the mixed design: between- and within-subjects for this study, for we aimed to compare results from two different research groups, that were the experiment group (which was assigned the written emotional disclosure task) and the control group (which was assigned to write about control topics); and results from the participants within the same group.

Instrument and Measurement. Writing manipulation. For 3 consecutive days, participants from the experiment group were asked to "let go and write about the deepest thoughts and feelings" regarding their relationship by involving as deep and as much emotions as possible, while the control group were asked to develop rational and logical arguments without involving and expressing any personal emotions regarding the assigned control topics, which were about the internet use in Indonesia, the inclusion of sex education in universities curriculum, and whether life is fate or a choice. This manipulation was checked using three 4 -scale questions $(1=$ not at all, $4=$ very much) which asked the participants to rate just how "meaningful", "personal", and "revealing of your emotions" their writings were.

Subjective distress. This study adapted the Impact of Events Scale (Horowitz et al, 1979) that contained two subscales, intrusion and avoidance, to assess participants' subjective distress on the first day of the experiment, prior to the writing session, and the last day, after the writing session. The scale is a self-report instrument consisting of 15 items measuring the level of subjective distress in forms of intrusive thoughts and avoidance related to the heartbreak experienced in the last seven days. The scale was adapted by adjusting the scale items to events that are relevant with the research, which is heartbreak. This scale has good reliability $(\alpha=0,86)$.

Mood. Participants' mood were assessed every day after the writing session using the revised version of the Profile of Mood States which consists of five negative affect subscales (tension, depression, fatigue, confusion, and anger) and two positive affect subscales (vigor and esteem-related) (Grove \& Prapavessis, 1992). The scale is not only designed to measure the positive and negative affects represented by the six subscales, but also to measure Total Mood Disturbance (TMD), a general estimation of one's affective state. This study used the TMD calculation as the mood measurement by subtracting the positive subscales score from the sum of negative subscales scores. A high score of TMD indicates a more negative emotional state (higher mood disturbance). The scale has good reliability $(\alpha=0,93)$.

Procedure. Individuals who agreed to participate were scheduled for three 50-minute appointments each in three consecutive days, which were adjusted to their choice of time and availability. Randomization to condition was conducted prior to the participants' arrival. For all participants, the experiment took place in a computer laboratory, with the experiment group assigned to computers on the left side row and the control group on the right side. After reading and signing the consent form, the participants were instructed to open the web browser in their computers, in which three 
webpages containing the questionnaires and the writing task had been previously prepared. On the first day, the participants completed the Impact of Events Scale which assessed their current level of subjective distress, followed by the 20-minute writing session. Following standard procedures (Pennebaker, 1997), participants assigned to the WED condition were asked to write about their heartbreak experience with as much emotions and feelings as possible; whereas the participants in the control group were asked to write about the control topics without describing any emotions or opinions. The session was followed by a manipulation check, and finished by the Profile of Mood States questionnaire assessing their current mood states after the writing session.

On the second day, participants went straight to the writing session and completed another mood measurement; and for the last day, same procedure was applied but with the post-test assessment of subjective distress at the very end of the session. The participants were then debriefed and rewarded with small souvenirs.

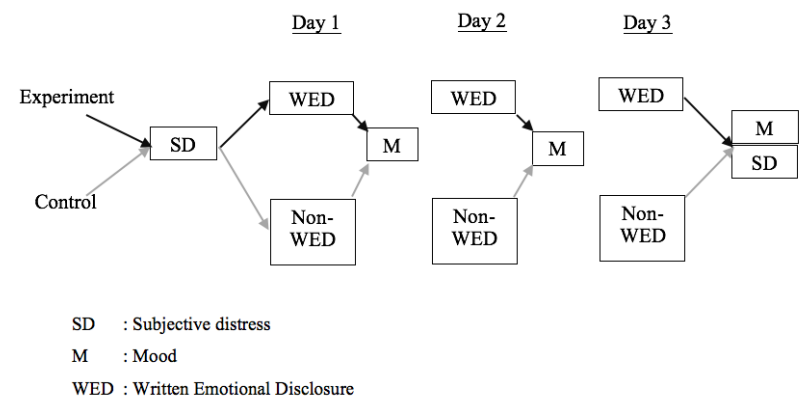

Figure 1. Scheme of the experiment's procedure.

\section{Results}

Manipulation check. As shown in Table 1, participants in the WED condition rated their essay as significantly more meaningful, more personal, and more revealing of their emotions than did the participants in the control condition. This indicated that the manipulation applied to the study had succeeded.

Effects of Written Emotional Disclosure on Subjective Distress and Mood. The independent sample t-test results shows that the difference of subjective distress scores between participants who wrote about their heartbreak $(M=8,23 ; S D=$ $15,34)$ is not statistically significant $(t(41)=0,396$; $p>0,05)$ than the participants who wrote about the control topic $(M=6,76 ; S D=7,9)$. Whereas, the result from mixed ANOVA shows that there are effects from Time of Writing on participants'
$\operatorname{mood}(F(1,6,65,8)=10,98, p<0,001$. The contrast shows that throughout the three days of writing session, there were improvements on participants' mood from the first day to the second day $F(1,665,8)=14.77, r=.265$, and improved even more on the third day $\mathrm{F}(1,6,65,8)=5,68, r=$ 0,12 . However, there was not any significant effect of WED, which suggested that the mood on both participants in the experiment and control group are in general, the same $F(1,41)<1, r=0,044$. In addition to that, there isn't any significant interaction between Time of Writing and WED $F(1,6,65,8)=3,12$. This findings suggested that the improvement of participants' mood after every writing sessions did not differ across groups.

Table 1.

Manipulation Check on Essay Content

\begin{tabular}{ccccccc}
\hline Condition & N & Day & Mean & SD & $\begin{array}{c}\text { t- } \\
\text { stat }\end{array}$ & p-value \\
\hline \multirow{2}{*}{$\begin{array}{c}\text { Experi- } \\
\text { ment }\end{array}$} & 22 & 1 & 9,1 & 2,5 & 4,7 & $\mathrm{p}<0,05$ \\
& & 3 & 8,7 & 2,6 & 2,4 & $\mathrm{p}<0,05$ \\
& & 1 & 5,2 & 2,9 & 4,7 & $\mathrm{p}<0,05$ \\
Control & 21 & 2 & 6,9 & 2,4 & 2,4 & $\mathrm{p}<0,05$ \\
& & 3 & 5,3 & 2,5 & 4,3 & $\mathrm{p}<0,05$ \\
\hline
\end{tabular}

Table 2.

Independent Sample t-Test Result on Subjective Distress

\begin{tabular}{cccccc}
\hline Condition & N & Mean & SD & t-stat & $\begin{array}{c}\boldsymbol{p} \text { - } \\
\text { value }\end{array}$ \\
\hline Experiment & 21 & 8,23 & 15,34 & 0,396 & $\mathrm{p}>$ \\
Control & 22 & 6,76 & 7,9 & & 0,05 \\
\hline
\end{tabular}

Table 3.

Mixed ANOVA Result on Subjective Distress

\begin{tabular}{lcc}
\hline \multicolumn{1}{c}{ F } & $\boldsymbol{p}$-value \\
\hline Within-Subjects Effects & & \\
Time & 10,998 & $\mathrm{p}<0,001^{*}$ \\
Time x Group & 3,121 & $\mathrm{p}>0,05$ \\
Between-Subjects Effects & & \\
Group & 0,079 & $\mathrm{p}>0,05$ \\
\hline
\end{tabular}

\section{Discussion \& Conclusion}

Discussion. Findings of this study showed that subjective distress and mood of the participants in 
the WED condition and the control condition did not differ significantly. In other words, writing about stressful events (as in this case, heartbreak) did not have any significant impact on participants' subjective distress and mood. One of the major things we assumed may be the cause of the incongruity of our hypothesis and our result, is time, or to be precise, the interval between our writing sessions and our measurements. In our study, participants' subjective distress were measured immediately after they finished their writing task, whereas in previous studies, the posttests/follow-up assessment were always conducted 4 to 15 weeks after. Pennebaker (1986) stated that the effects from WED are not immediate, thus suggesting that longer intervals between writing and measurements might show different results.

Another assumption about time is the duration of the heartbreak (3-month time) which we predicted were way too long to be able to show the expected effect of the study. There might be possibilities that participants had gradually adapted to their heartbreak, resulting in their subjective distress and mood disturbance that were not on the level that could be significantly impacted by WED. Related to participants' report on their subjective distress, we assumed that mere self-report instruments were rather unable to measure what participants really feel, especially about their subjective distress linked to their heartbreak. We thought that it could be more effective if the assessments had been done differently, such as one on one intensive interview.

One thing that we found from the results of our study is that, aside from what the participants wrote in their essays (heartbreak experience or control topics), their 3-day writing sessions improved their mood, nevertheless. This result is in line with the findings that expressing emotions in written forms facilitates cognitive process from one's traumatic memories, which then lead to not only physiological changes but also affective changes (Pennebaker, 1989). To be even more precise, WED leads to the conversion or the transformation of traumatic events into a linguistic structure which supports assimilation process and one's understanding about the event, and reducing negative affects related to the same matter (Pennebaker, Mayne, \& Francis, 1997).

Changes of mood scores in the control group that are convergent with the experiment group's were probably caused by the writings from the control group that were not entirely neutral from any emotions and opinions, and were not entirely free from thought process that were similar to it was of the experiment group. We assumed that our choice of control topic assigned to the control group weren't necessarily the most neutral ones that were able to fully "prevent" the control group participants from emotional, subjective thoughts, thus failed to show mood improvements that are contrast to the other groups. On the other side, we considered that some content analysis might become an effective method to discover unseen shifts of mood and other intense feelings involved in the participants' writing.

Conclusions. Based on our analysis, we conclude that there were no effects of written emotional disclosure on subjective distress and mood among individuals experiencing heartbreak. This result suggests that writing from time to time can improve one's mood, regardless of the topic of the writing.

\section{References}

American Psychological Association (Ed.). (2009). APA college dictionary of psychology (1st ed). Washington, DC: American Psychological Association.

Baikie, K. A., Geerligs, L., \& Wilhelm, K. (2012). Expressive writing and positive writing for participants with mood disorders: An online randomized controlled trial. Journal of Affective Disorders, 136(3), 310-319.

Baum, A., Cohen, L., \& Hall, M. (1993). Control and intrusive memories as possible determinants of chronic stress. Psychosomatic Medicine, 55(3), 274-286.

Coggins, J., \& Fox, J. R. E. (2009). A qualitative exploration of emotional inhibition: a basic emotions and developmental perspective. Clinical Psychology \& Psychotherapy, 16(1), 55-76. https://doi.org/10.1002/cpp.604

Colman, A. M. (2006). Oxford Dictionary of Psychology. 2006.

Erikson, E. H. (1968). Identity: Youth and crisis. New York: Norton.

Gallagher, R. P. (2015). National survey of college counseling centers 2014. Retrieved from http://d-scholarship.pitt.edu/id/eprint/28178

Grandi, S., Sirri, L., Wise, T. N., Tossani, E., \& Fava, G. A. (2011). Kellner's Emotional Inhibition Scale: A Clinimetric Approach to Alexithymia Research. Psychotherapy and Psychosomatics, $80(6)$,

335-344. https://doi.org/10.1159/000328576

Grove, R., \& Prapavessis, H. (1992). Preliminary evidence for the reliability and validity of an abbreviated Profile of Mood States. 
International Journal of Sport Psychology, 23(93), 109.

Guastella, A. J., \& Dadds, M. R. (2008). Cognitivebehavioural emotion writing tasks: A controlled trial of multiple processes. Journal of Behavior Therapy and Experimental Psychiatry, 39(4), 558-566.

https://doi.org/10.1016/j.jbtep.2007.11.008

Horowitz, M. J. (1986). Stress-response syndromes: A review of posttraumatic and adjustment disorders. Psychiatric Services, 37(3), 241-249.

Horowitz, M., Wilner, N., \& Alvarez, W. (1979). Impact of Event Scale: a measure of subjective stress. Psychosomatic Medicine, 41(3), 209218.

Lazarus, R.S., Folkman, S. (1984). Stress: appraisal and coping. Springer New York.

Lepore, S.J. and Helgeson, V. (1998). Social constraints moderate the relation between intrusive thoughts and mental health in prostate cancer survivors. Journal of Social and Clinical Psychology, 17, 89-106.

Lepore, S. J., \& Greenberg, M. A. (2002). Mending Broken Hearts: Effects of Expressive Writing on Mood, Cognitive Processing, Social Adjustment and Health Following a Relationship Breakup. Psychology \& Health, 17(5), 547-560. https://doi.org/10.1080/08870440290025768

Murti, R. D. (2012). Pengaruh Expressive Writing terhadap Penurunan Depresi pada Remaja SMK di Surabaya. Jurnal Psikologi Klinis Dan Kesehatan Mental, 1(2). Retrieved from http://journal.unair.ac.id/filerPDF/110710193_7 v.pdf

Pennebaker, J. W., \& Beall, S. K. (1986). Confronting a traumatic event: toward an understanding of inhibition and disease. Journal of Abnormal Psychology, 95(3), 274.

Pennebaker, J. W., \& Francis, M. E. (1996). Cognitive, Emotional, and Language Processes in Disclosure. Cognition and Emotion, 10(6), 601626. https://doi.org/10.1080/026999396380079

Pennebaker, J. W., Mayne, T. J., \& Francis, M. E. (1997). Linguistic predictors of adaptive bereavement. Journal of personality and social psychology, 72(4), 863.

Pennebaker, J. W. (1989). Cognitive, inhibition, and disease. In L. Berko- witz (Ed.), Advances in experimental social psychology (Vol. 22, pp. 211-244). New York: Academic Press.

Petrie, K. J., Booth, R. J., Pennebaker, J. W., Davison, K. P., \& Thomas, M. G. (1995). Disclosure of trauma and immune response to a hepatitis $\mathrm{B}$ vaccination program. Journal of Consulting and Clinical Psychology, 63(5), 787.

Purwandari, E., \& Hadi, S. (n.d.). Pengaruh Menulis Pengalaman Emosional Terhadap Memori Otobiografi dan Depresi Pada Remaja yang Menjalani Rehabilitasi NAPZA. Sosiosains, 18(2).

Reetz, D. R., Barr, V., \& Krylowicz, B. (2014). The association for university and college counseling center directors annual survey. Aurora, 51, 60506.

Sindoro, L. F. (2017). The Effectivenss of Expressive Writing as a Reductor of Psyhchological Distress. UI Proceedings on Social Science and Humanities, $1 . \quad$ Retrieved from http://proceedings.ui.ac.id/index.php/uipssh/arti cle/view/79

Sloan, D. M., \& Marx, B. P. (2004). A Closer Examination of the Structured Written Disclosure Procedure. Journal of Consulting and Clinical Psychology, 72(2), 165-175. https://doi.org/10.1037/0022-006X.72.2.165

Sloan, D. M., Marx, B. P., \& Epstein, E. M. (2005). Further Examination of the Exposure Model Underlying the Efficacy of Written Emotional Disclosure. Journal of Consulting and Clinical Psychology, 73(3), 549-554. https://doi.org/10.1037/0022-006X.73.3.549

Sloan, D. M., Marx, B. P., \& Epstein, E. M. (2007). Does altering the writing instructions influence outcome associated with written disclosure? Behavior Therapy, 38(2), 155-168.

Smyth, J. M. (1998). Written emotional expression: effect sizes, outcome types, and moderating variables. American Psychological Association. Retrieved from http://psycnet.apa.org/journals/ccp/66/1/174/

Smyth, J. M., Hockemeyer, J. R., \& Tulloch, H. (2008). Expressive writing and post-traumatic stress disorder: Effects on trauma symptoms, mood states, and cortisol reactivity. British Journal of Health Psychology, 13(1), 85-93. https://doi.org/10.1348/135910707X250866

Swanbon, T., Boyce, L., \& Greenberg, M. A. (2008). Expressive writing reduces avoidance and somatic complaints in a community sample with constraints on expression. British journal of health psychology, 13(1), 53-56.

Terry, P. C., Lane, A. M., Lane, H. J., \& Keohane, L. (1999). Development and validation of a mood measure for adolescents. Journal of sports sciences, 17(11), 861-872.

Wright, J. (2002). Online counselling: Learning from writing therapy. British Journal of Guidance and Counselling, 30(3), 285-298. 